\title{
ALGUNAS ANOTACIONES AL PENSAMIENTO TEOLÓGICO DE MARÍA ZAMBRANO
}

\author{
JUANA SÁNCHEZ-GEY VENEGAS \\ Universidad Autónoma de Madrid
}

\begin{abstract}
RESUMEN: María Zambrano reflexiona sobre algunas preocupaciones que siempre le han interesado: el cristianismo y la mística, las procesiones o misiones divinas, la encarnación de Cristo, la Virgen, la liturgia, entre otras vivencias personales. Se descubre en su pensamiento de modo sobresaliente la búsqueda del Espíritu como fundamento del conocimiento, por lo que se podría llegar a decir que esta vivencia contribuye y da pie al rechazo del racionalismo y del materialismo en su concepción de la filosofía.
\end{abstract}

PALABRAS CLAVE: filosofía y teología; mística; el cristianismo; el Espíritu Santo.

\section{Some remarks on theological thought of Maria Zambrano}

ABSTRACT: Maria Zambrano reflects upon some of the problems she has been always interested in: Christianity and Mysticism with especial emphasis on the divine processions, the Incarnation of Christ the Virgin Mary, the liturgy among other personal experiences. In these letters the pursuit for the Holy Spirit as the foundation of knowledge is remarkably noticeable, so that it could be argued that this experience contributes and gives rise to the rejection both of rationalism and of materialism of the philosophy.

KEY WORDS: Philosophy and Theology; Mysticism; Christianity; Holy Spirit.

\section{INTRODUCCIÓN}

Actualmente el pensamiento de María Zambrano goza de una gran difusión y reconocimiento, no obstante consideramos que su pensamiento teológico no ha sido analizado. Algunos estudiosos como Juan Fernando Ortega Muñoz, José Demetrio Jiménez Sánchez-Mariscal, María Cobos, Luis Llera, Sánchez Orantos o Carmen Víllora han estudiado el pensamiento religioso ${ }^{1}$; sin embargo, no nos consta que se haya estudiado su reflexión acerca de la teología católica. Sólo el catedrático de filosofía de la universidad de Málaga y gran amigo de María Zambrano, Juan Fernando Ortega Muñoz, ha escrito el artículo El Dios del horizonte. Estudio sobre el pensamiento teológico de María

\footnotetext{
1 Ortega Muñoz, J. F., María Zambrano. Málaga: Arguval, 2006; Jiménez SÁnchezMariscal, J. D., Los senderos olvidados de la filosofía. Una aproximación al pensamiento de María Zambrano, Religión y Cultura. Madrid, 1991 y «El pensamiento de María Zambrano: Una entrañable mirada de lo humano" Religión y Cultura, XLII, 1996, p. 377-382; CовоS NAVIDAD, M., "Recuperar "lo divino en el hombre". Reflexión en torno a la obra de María Zambrano El hombre y lo divino», en MuRILlo, I. (ed.) Filosofía contemporánea y cristianismo: Dios, hombre, praxis. Madrid: Diálogo Filosófico, 1988; Llera, L., La razón humilde. María Zambrano y la tradición mística española, Revista de Exilios. Madrid, 2009; Sánchez Orantos, A., La experiencia de Dios como fenómeno puro: Una respuesta a la filosofía moderna de la religión (Tesis doctoral, 2014); Víllora Sánchez, C., El pensamiento religioso de María Zambrano, Academia de Hispanismo. Madrid, 2015.
} 
Zambrano ${ }^{2}$, pero este estudio no se refiere a la teología católica sino que se ha centrado en una reflexión magnífica sobre El hombre y lo divino (1955) que, a nuestro parecer, sigue siendo un estudio del hecho religioso o de la fenomenología de la religión acerca de la obra de la filósofa.

Consideramos que el pensamiento teológico de Zambrano, aunque no exclusivamente, se encuentra el epistolario mantenido con un joven sacerdote católico, Agustín Andreu (teólogo y filósofo, nacido en 1928)³ al que conoce en Roma en los años cincuenta y con el que, posteriormente, establece una larga correspondencia. Esta comienza en octubre de 1973 hasta primeros de abril de 1976. El epistolario ha sido editado por Agustín Andreu en $2002^{4}$ y recoge 78 cartas enviadas por María Zambrano. Hasta ahora no han sido editadas las que Andreu le dirige a la filósofa. También en esta obra se publican unos anexos, breves estudios sobre algunos de los temas tratados, los cuales son interesantes porque añaden información o la exponen con detalles relevantes. Agustín Andreu los llama Anotaciones Epilogales a un método o camino. La obra contiene también un índice temático de cada una de las cartas.

La importancia de dar a conocer el pensamiento teológico de Zambrano se funda en que aún queda material inédito por publicar y, a pesar de que se han editado cuatro volúmenes de sus Obras Completas, vemos que sigue sin analizarse el componente teológico de su filosofía ${ }^{5}$. Entre los estudiosos de la autora, Sebastián Fenoy destaca que «La Fundación María Zambrano cuenta, entre los fondos de su archivo, con una colección de cartas que sobrepasa ampliamente los tres millares (3202), la gran mayoría de las cuales todavía permanecen inéditas ${ }^{6}$. Repasando la gran lista de los destinatarios se hace evidente que el que presentamos es un epistolario único en el tema ${ }^{7}$.

2 Ortega MuÑoz, J. F., «El Dios del horizonte. Estudio sobre el pensamiento teológico de María Zambrano» en Dios en el pensamiento hispano del siglo XX, (coord. Cabria, J. L y Sánchez-Gey, J). Salamanca: Sígueme, 2002, p. 179-203.

3 Agustín Andreu es autor de obras como: Lessing. Estudios filosóficos y teológicos, Anthropos, 1990; Shaftesbury. Crisis de la civilización puritana, Universidad Politécnica de Valencia, 2003; El cristianismo metafísico de Antonio Machado. Valencia: Pretextos, 2002 y María Zambrano. El Dios de su alma. Granada: Comares, 2007.

4 Zambrano, M., Cartas de La Pièce. Correspondencia con Agustín Andreu. Valencia: PreTextos, 2002.

5 A día de hoy se han publicado el volumen I que contiene los libros editados de 1930 a 1939; el II los editados de 1940 a 1950; el III los editados de 1955 a 1973 y el VI que contiene bastantes escritos autobiográficos de su producción filosófica desde 1928 a 1990 y Delirio y Destino que, es, en efecto, un ensayo autobiográfico. Todos los volúmenes de las Obras Completas se han editado en Galaxia Gutenberg, Barcelona, 2000-2014.

6 Fenoy, S., Obra inédita de María Zambrano, (tesis doctoral, 2008), p. 9.

7 «Entre los destinatarios se encuentran José Luis Abellán, José Bergamín, Camilo José Cela, Emile Cioran, Pablo de Andrés Cobos, Antonio Colinas, Enrique de Rivas, Rafael Dieste, Ramón Gaya, Alain Guy, José Lezama Lima, Antonio Machado, Victoria Ocampo, José Ortega Sporttorno, Juan Fernando Ortega Muñoz, Timothy Osborne, Octavio Paz, Gustavo Pittaluga, Emilio Prados, Alfonso Reyes, Alfonso Rodríguez Aldave, Pedro Salinas, Rafael Tomero, José Angel Valente, Joaquín Verdú, entre algunos otros más», Ibid, pp. 99-100. 
Mas no sólo es relevante este estudio por su novedad, sino que conviene destacar el interés de Zambrano acerca de las verdades de la fe católica y el estudio teológico de las mismas. De forma especial, su interés se centra en las procesiones divinas o en el modo de la relación ad extra de las Personas Divinas, es decir, en su acción hacia los hombres, y más en concreto en la acción del Espíritu Santo. Esta reflexión teológico-metafísica es el tema nuclear del epistolario citado y también lo es del pensar-sentir zambraniano en general, que busca conocer lo originario, compenetrarse con la inspiración y encontrar el sentido integrador del vivir humano.

Al mismo tiempo, hay también otros temas significativos como son la Encarnación de Cristo, la Virgen María, la liturgia en la recepción del Concilio Vaticano II, así como otros derivados de éstos que también revisten importancia: la relación entre filosofía y teología, el desprendimiento de sí misma, la purificación y algunos otros que significan o hacen de esta correspondencia una de las más conmovedoras y hondas de la reflexión zambraniana.

Hemos de destacar la estrecha relación entre filosofía, religión y mística en toda la obra de María Zambrano. Pensamos que la filosofía de la autora se sitúa en las siguientes coordenadas históricas: a) una filosofía de la crisis y, por tanto, una propuesta de filosofía como salvación; b) cuya reflexión busca orientar la vida humana, pero marcando una originalidad frente a Ortega al considerar la trascendencia como punto de apoyo de su pensamiento, que se abre a la religión y a la teología. Ciertamente, su filosofía es una respuesta vital o experiencial a la crisis histórica pero, distanciándose de Ortega, busca una palabra poética. Palabra creadora que contiene fe en lo que se sueña y esperanza para asumir los proyectos con fortaleza y seguridad.

La aportación de la pensadora a la historia del pensamiento consiste en que considera que a la filosofía le sucede lo mismo que a la mística, porque «el místico ha de ser por fuerza filósofo o pensante» ${ }^{8}$. Para María Zambrano la filosofía es una preparación para la vida y piensa que en el transcurso de la vida hay momentos en los que se puede perder todo: favores, prestigios, privilegios, que podríamos haber pensado que nos eran propios. Si entonces el ser humano no se propone el desprendimiento, difícilmente podrá superarse y vivir la vida en lo que también tiene de dolor y de esperanza. De aquí que María hable tanto de las emociones y sentimientos como del vacío y de la angustia, que son mediaciones que ayudan a lograr el hecho de ser personas, pues todo desarraigo convoca a la unidad. La radicalidad de la filosofía exige abandono para alcanzar lo importante. Esto es la trascendencia.

El saber que busca requiere la unidad de pensar y sentir que Zambrano defiende. Esta sabiduría propone otra metodología, diferente del mero conocimiento, como señala en Notas de un método (1989). La sabiduría tiene como raíz la esperanza, pues ninguna realidad es neutra y el ser humano anhela infinitamente. Junto a la esperanza, María Zambrano apuesta por la fe. La fe,

8 Zambrano, M., Los bienaventurados. Madrid: Siruela, 1990, p. 77. 
dice, es el argumento de las cosas que se esperan, tal como corrobora el pensar bíblico. De este modo, la esperanza alienta el pensar y la vida, es puente entre la acción y la pasividad, entre la fe y la indiferencia, pues la vida humana no se sacia con el solo vivir, el ser del hombre exige la realización plena.

Sus obras de contenido religioso son entre otras: La Agonía de Europa (1945), El hombre y lo divino (1955) y Los Bienaventurados (1990). En la primera afirma que conviene abandonar el naturalismo y el liberalismo porque ponen toda la confianza en los hechos y en la naturaleza humana, sin ninguna otra interpretación. Se vive «aferrado a los hechos» sin apertura a la trascendencia. Zambrano comienza su obra manifestando el rechazo a «la orfandad de Europa», que camina confusa y deshumanizada. Su propuesta es teocéntrica, pues a la manera de San Agustín, con quien dialoga, busca La ciudad de Dios que sitúe la misericordia frente a la soberbia y a la violencia humanas. Zambrano recomienda el rechazo del subjetivismo, de la ausencia de valores, de la relativización moral de una Europa agónica que se encuentra desagarrada, en parte, por el racionalismo y, en parte también, por el subjetivismo. La recuperación de Europa sólo puede lograrse si se vuelve a los principios fundamentales, es decir, a las raíces grecocristianas, al cristianismo y a la cultura griega. Por tanto, conviene abandonar el naturalismo y el liberalismo, como hemos dicho, pues la "genialidad de Europa parecía consistir, en gran parte, en la capacidad de desasimiento de la realidad ${ }^{9}$. Este desasirse para asirse a lo realmente importante es un sentimiento que, como un talismán, da a María Zambrano fuerza y luz; guía y ensancha el horizonte de su pensamiento. Esta es la raíz de la razón poética que se abre a la mística.

La propuesta filosófica de Zambrano es la de una filosofía como mediación, acogedora del sentido histórico de una religión cuyo Dios se encarna y es misericordioso. De este modo, se distancia de la mentalidad de un Dios constructor o hacedor y de una idea de Europa eminentemente productiva que tiene una visión del Dios cristiano empobrecida y poco humanizada. Este ideal de la filosofía como salvación le lleva al diálogo con la religión en las obras de San Agustín y de Santo Tomás, que se esforzaron en servir «de mediación entre la infinitud divina y el hombre ${ }^{10}$. Zambrano valora esta mediación católica que aúna la razón y el amor y promueve, así, una razón humanizada, encarnada y misericordiosa. Contraria, pues, a la violencia y la soberbia de una razón absolutizadora.

En El hombre y lo divino (1955) distingue entre lo sagrado y lo divino: áquel es el fondo de la realidad, el principio de donde todo surge; lo divino se da al hombre experiencialmente, mediante una revelación. Subraya el sentir originario como poiesis, unión sagrada, capacidad creadora. Por ello destaca el sentido relacional entre la criatura y el Creador: «Mas aceptar lo divino de verdad es aceptar el Misterio último... El hombre se niega a padecer a Dios y

9 Zambrano, M., La agonía de Europa. Madrid: Mondadori, 1988, p. 11.

10 Ibid, p. 35. 
a lo divino que en sí lleva» ${ }^{11}$. Ahora bien, si el ser humano no vive este sentido experiencial entonces se cuantifica y se degrada, se deifica a sí mismo y se llena de soberbia queriendo sobrepasar sus propios límites, de este modo ni es propiamente humano ni es un dios.

Sin embargo, el sentir relacional que Zambrano propone es delirio y esperanza, es sentirse mirado por los dioses antes que toda otra emoción. Le acompaña la esperanza pues el ser humano no se siente "arrojado a la tierra» porque «es dentro de sí, donde siente esa realidad suprema que le impulsa y le lleva sobre todo obstáculo» ${ }^{12}$. Lo divino supone un don que se recibe, condición pasiva o gratuita que se le entrega para su realización personal y social. De este modo se explica la importancia que Zambrano concede a la filosofía y a la poesía, pues el ser humano busca este don recibido, que la poesía expresa de mil maneras. En definitiva, el sentir originario es primigenio y en él se descubre a Dios como principio y fundamento. Esta experiencia humana que Zambrano defiende es el sentir filosófico o razón poética, unitiva y creadora, mística que se constituye como saber de salvación.

El desarrollo de este análisis supone el carácter teologal del pensamiento zambraniano, pues propone que lo divino se vive de modo experiencial. En este sentido, esta obra se convierte en una historia de las religiones o una fenomenología del hecho religioso, pues la filósofa defiende categóricamente que «una cultura depende de la calidad de los dioses». Ensalza el cristianismo, que analiza desde diferentes perspectivas, y en su artículo «Dios ha muerto» recorre el pensamiento de ateos sobresalientes para exponer que el cristianismo es la única religión en la que «Dios muere a manos de los hombres» y que sólo se puede entender plenamente el «Dios ha muerto» cuando es el Dios del amor quien muere, pues sólo muere en verdad lo que se ama...lo demás desaparece ${ }^{13}$. Antes se hablaba de destrucción, a partir del cristianismo se puede hablar de muerte.

La obra Los Bienaventurados, publicada al final de su vida aunque escrita en los sesenta y a comienzos de los setenta, habla del exilio y, preferentemente, de la condición humana. En el prólogo se refiere al Maestro que bajó a la tierra «dándonos a la par el absoluto y la relatividad pertinente», así en Cristo se unen lo más concreto y encarnado con la trascendencia más sagrada y eterna. El bienaventurado alcanza la unidad, porque acepta la realidad sin excluir la dicha y el dolor. En el pathos el ser humano conoce al Absoluto, el que sufre es «el hombre en quien el ser verdadero es más que el ser» ${ }^{14}$. Zambrano no propone la identidad, sino que entiende que el ser del sujeto humano aspira siempre a algo más. Los caracteres del ser personal son: el padecer, la mediación y la desposesión. El padecimiento comporta una interiorización imprescindible para el desarrollo personal que progresa gracias a la mediación o carácter relacional del ser personal, y todo ello convoca al horizonte perceptible para

\footnotetext{
11 Zambrano, M., El hombre y lo divino. México: Fondo de Cultura Económica, 1955, p. 258.

12 Ibid, p. 34.

13 Ibid, p. 145.

14 Zambrano, M., Los Bienaventurados, op. cit., p. 30.
} 
que abandone lo superfluo e innecesario a fin de alcanzar la dimensión ética de la vida humana y hasta la mística.

Trata, por tanto, de la condición humana y su propuesta es manifiesta: el padecer como mediación y ésta como apertura a la trascendencia. Por ello, el bienaventurado es aquel que, abismado en su destierro y desposesión, anhela el Absoluto. Zambrano le da a esto último un nombre concreto: Padre. Desde los años cuarenta exalta esta búsqueda en El pensamiento vivo de Séneca (1944). Su llamada a la desposesión o purificación es camino obligado para alcanzar la unidad del pensar y sentir, la trascendencia. Subraya la condición creatural del ser humano y así describe la desposesión, la mediación filial y el hallazgo. Por ello habla de una fe como vivencia y garantía de su felicidad bienaventurada. El logro de la razón poética ha sido hallar la síntesis de la filosofía, la religión y la mística que en esta obra se alcanza.

Porque el hombre se padece a sí mismo y por lo que ve. Lo que ve le hiere, le puede herir aún prodigiosamente para que su ser se le abra y se le revele, para que vaya saliendo de la congénita oscuridad a la luz, esa que hirió sus ojos - heridas- cuando los abrió por primera vez, cuando salió de su sueño o vio su sueño ${ }^{15}$.

Aunque hemos señalado sus obras con un contenido claramente religioso, podemos decir que la trascendencia recorre toda su creación y resulta ser el germen de la razón poética. En Notas de un método (1989) afirma que el Modelo de su pensamiento es Cristo. "Cuando el absoluto intangible e inasequible para el hombre, el santo sin sombra, sin mezcla, dice de sí mismo "soy el camino, la verdad y la vida", cuando el absoluto desciende a ser el camino de la verdad inasequible y de la vida que se hace verdadera, para el hombre el camino es trascenderse a sí mismo» ${ }^{16}$. Resulta difícil encajar que el pensamiento religioso y la búsqueda constante de la trascendencia presente en sus obras no hayan sido atendidos suficientemente, ya que esta vinculación hacia Dios se manifiesta de muchas maneras. Zambrano alimenta en sí la experiencia religiosa, la vivencia primera u originaria, el paraíso perdido, que resulta ser una metafísica de lo sagrado que pudiera traer a la modernidad un pensamiento más personal y más social, más ecuménico y más habitable, una verdadera experiencia mística y transformadora de lo más integrador de la condición humana que lleve aparejado un compromiso de vida. Así dice en Notas de un método que busca siempre la «vibración máxima», el "palpitar primario», es decir, desea una originaria vivencia, un vínculo con ese sentir primero que es, antes de todo, nacimiento. De aquí que le interese la filosofía como salvación, porque busca en la entraña humana el compromiso y la liberación de sí mismo, la relación fraterna con los otros, una relación que ha de ser entrañable, misericordiosa y compasiva.

Claros del Bosque (1977) es también una obra representativa del rechazo del nihilismo y del escepticismo, pues los claros se refieren a la síntesis de

15 Idem.

16 Zambrano, M., Notas de un método. Madrid: Mondadori, 1989, p. 78. 
vida y pensamiento, constituyen el a priori de una filosofía que se origina en la palabra reveladora, puesto que el ser humano no sólo es pregunta, sino que requiere respuesta. Y esta respuesta la encuentra en la mística, de la que subraya algunas características como el anhelo del misterio y de ahí el rechazo del racionalismo que habita toda su filosofía. Su apoyo al pensamiento intuitivo y la búsqueda del centro que es la raíz y el acto esencial de la persona. Prima la intuición que es el sentir originario. Y al mismo tiempo su descubrimiento de lo divino, la piedad y el amor. Por ello la antropología, la filosofía educativa y la política están preñadas de esta reflexión. Los grandes temas que propone son: la mística como humanización y el sentido cristiano de la mística: «Y como eje de todo, la idea cristiana del hombre como un ser que muere y ama, que muere con la muerte y se salva con el Amor ${ }^{17}$.

\section{Algunas anOtaciones PROPIAMENTE TEOLÓGICAS EN SU PENSAMIENTO FILOSÓFICO}

En el epistolario podemos observar las lecturas de Zambrano y su conocimiento de autores como: Plotino, el pensamiento gnóstico, San Agustín, la Escuela de Alejandría y San Clemente, así como de algunos Padres de la Iglesia. También percibimos algunas prácticas religiosas en la filósofa como los rezos, la atención al santoral de cada día, las jaculatorias que pronuncia, etc. Todo ello nos lleva a dilucidar el conocimiento y la estima de la fe católica en su vida y en su obra. No obstante, en muchas ocasiones, afirmará que ella no es teóloga, como anteriormente Santa Catalina de Siena y Santa Teresa de Jesús lo habían dicho de sí mismas. Lo cual no obsta para ver la profundidad de sus reflexiones.

Señalaremos algunos de los aspectos de las Cartas de La Pièce, mediante estas reflexiones teológicas:

\section{a) La relación entre filosofía y teología}

En este epistolario, Zambrano se sitúa en un locus claramente teológico ya desde la primera carta, fechada el 4 de octubre de 1973: "El amor que circula, como el Verbo, juntos los dos ${ }^{18}$. Hace mención especial de Clemente de Alejandría (150-215), pues su filosofía refuerza la conciliación entre revelación cristiana y filosofía griega, que no opone aunque reconoce la primacía de la fe respecto a la filosofía. También conviene señalar el Corpus areopagiticum del Pseudo-Dionisio, neoplatonizante, pues da importancia a la mística y señala tres caminos para la experiencia de Dios: la teología afirmativa, la teología negativa y la vía mística, esta última trata la unión del hombre con Dios.

17 Zambrano, M., Hacia un saber sobre el alma. Madrid: Alianza Editorial, 1986, p. 21.

18 Zambrano, M., Cartas de La Pièce, op. cit., Carta nº 1, p. 27. 
La filosofía griega de la que me sabes devota, no pudo llegar a esa revelación del hombre. Y bien, justo ahora, esa revelación tiene que ser reiterada, revivida. Insisten en la «idea» de Dios, y hasta en el concepto. Si por concepto entendiesen la concepción... ${ }^{19}$

María Zambrano defiende la vivencia, no el concepto. Concebir consiste en dar forma a la inteligencia, es dotar de sentido a la realidad. Así el pensamiento teológico supone una concepción relacional de apertura entre Dios y el ser humano y ello nunca puede referirse a una realidad estática, cerrada, sino que supone una dimensión abierta, en movimiento. Se quiere hacer el esfuerzo por tratar de argumentar esta comprensión de la relación que es siempre dinámica y no clausurante. También destacaremos la carta tercera, del 28 de abril de 1974, en la que se habla de la Trinidad, en sentido vivencial y ontológico: «tus palabras acerca de la circulación sacratísima, santísima, divina entre el Verbo y el Espíritu me parece que es de primer orden ${ }^{20}$. Desde entonces, María denominará «la perla» a esta visión originaria o comunicación ente el Logos y el Espíritu, que, como perla preciosa, algunos han reconocido y han saboreado vivencialmente

Así, toda la vida cristiana es comunión con cada una de las personas divinas, sin separarlas de ningún modo. El que da gloria al Padre lo hace por el Hijo en el Espíritu Santo; el que sigue a Cristo, lo hace porque el Padre lo atrae y el Espíritu lo mueve. ${ }^{21}$

Esta antropología teológico-filosófica supone una concepción del hombre como ser espiritual. Por ello reconoce a Clemente de Alejandría, escritor eclesiástico del siglo III, pues desarrolló un cristianismo humanista o de encarnación del Logos. También estudia el movimiento mesaliano (siglos III y IV), que posteriormente fue condenado como herético, y el movimiento joánico del Asia Menor (Éfeso), que da origen a toda la literatura monacal de los siglos IV y V, que contará en su desarrollo histórico con santos como San Benito y, posteriormente, San Francisco.

La afirmación de la inhabitación de la Trinidad en el ser finito personal supone, por tanto, poder explicar el origen del conocimiento como espiritual: «La inteligencia se alimenta del alma», dirá Zambrano y «el pensar viene del espíritu», dirá Andreu. En efecto, la presencia del Absoluto en el espíritu humano permite dar cuenta de una realidad que precede a toda experiencia humana y que es el origen del pensar, del hacer y del amar humanos ${ }^{22}$.

\section{b) El hombre como ser personal}

En su carta primera dice: "Inútil decirte que sin lo divino para mí no hay hombre posible, ni para nadie. Y no se trata de un nuevo "humanismo", ni de

19 Ibid, Carta n ${ }^{\circ}$ 3, p. 33.

$20 \quad$ Ibid, Carta $n^{\circ} 3$, p. 33.

21 Zambrano, M., Cartas de La Pièce, op. cit., p. 27.

22 Rielo, F., Concepción mística de la Antropología. Madrid: Fundación Fernando Rielo, 2012. 
ningún ismo»; de este modo, ante tanta antropología vacía o huera, reivindica: "Sólo el hombre entero y verdadero», y es en esa vivencia de lo verdaderamente humano donde está la huella de lo divino, la que también le salva de los partidismos de los que siempre huyó tanto en la política, como de los géneros, o también de las religiones en su sentido corporativo, o competitivo, pero nunca se alejó de lo realmente humano en su intimidad constitutiva ${ }^{23}$.

Zambrano defiende la relación que es inmanente y trascendente: la inmanencia que supone un movimiento o salida del alma de sí misma para compenetrarse con la trascendencia conlleva la propia realización del ser humano en su integridad total. Habla mucho de la integridad, el mismo Andreu se extraña de su defensa constante y que la asemeje incluso a la virginidad, que resalta en personajes como Antígona o la Virgen María. Parece que esta virtud es la que defiende cuando se refiere a su separación matrimonial, pues dice que estaría dispuesta al divorcio siempre que no comprometa a su pertenencia a la Iglesia Católica: «El bautismo no me lo ha podido quitar» ${ }^{24}$. La integridad recuerda a la autenticidad orteguiana, aquel «fondo insobornable» que constituye la radicalidad humana y del que emana la mejor energía de sí mismo.

Nos serviremos de unas reflexiones de Karol Wojtila para comprender la concepción zambraniana del cuerpo humano:

1) El cuerpo es forma mediante la que se participa en el mundo. Según Zambrano, la razón poética como razón unitiva ejerce esta función de unión entre el cuerpo y la trascendencia, pues la condición humana se refiere al cuerpo, su sentir y la trascendencia.

2) El cuerpo es el primer hogar para recibir al mundo, si lo aceptamos el mundo se convierte en nuestro hogar. María Zambrano expresa repetidamente que ser hombre sólo se alcanza desde la aceptación de sí mismo: «No se es hombre simplemente por haber nacido hombre, sino cuando se asume el serlo». Esta toma de conciencia supone humanización o personalización. Lo refiere en El libro de Job y el pájaro (1969), pues el hombre es criatura inacabada y su realización procede de la disposición a acabar la obra que el creador ha comenzado en él.

3) El cuerpo da testimonio de que no somos origen de nosotros mismos. En varias obras como El freudismo, testimonio del hombre actual (1940), Poema y Sistema (1944) o Aparición histórica del amor (1945) reconoce la necesidad de tener modelos de conducta así como la responsabilidad y humildad de que "hemos sido engendrados», pues incluso el amor supone la revelación de ser la obra de alguien, que es más que serlo de algo. No se puede amar sin sentirse amado, así el amor nos convoca siempre a una acción originaria.

23 Zambrano, M., Cartas de La Pièce, op. cit. Carta, no 1, p. 27-28.

24 Ibid, Carta, $\mathrm{n}^{\circ}$ 11, p. 65. 


\section{c) La persona}

En la génesis del pensamiento de Zambrano se puede observar la forma concreta de acercarse y dar dignidad al ser humano. En su primera obra Horizonte del Liberalismo (1930) llama al ser humano "heterodoxo cósmico» porque habita en esta realidad, pero añora otra realidad, que siempre desea. Esta será siempre la concepción de Zambrano acerca de la persona humana, se sitúa en su experiencia concreta pero la ve en toda su amplitud. Por eso también la llama «criatura entre dos orbes». Desde sus primeras publicaciones Castilla a solas consigo misma (1928) y El espíritu de la liturgia (1933) ya deja claro que es cada ser humano concreto y sus necesidades quien le interesa realmente y no las realidades políticas. En los años treinta escribe Sobre una educación para la libertad (1934) y se refiere al compromiso de compartir con otros y saber renunciar a las propias cadenas, pues «La libertad es un acto de obediencia o sujeción a la vocación ${ }^{25}$. Por ello dice que la libertad no consiste en poseer sino que la persona se realiza en el compartir y en la donación a los demás, este compromiso humaniza a la persona. En La Agonía de Europa (1945) en el diálogo con San Agustín subraya, especialmente, la vivencia de la humildad, que no supone sólo una virtud frente a la soberbia, sino también la confianza en la relación con el Creador, como raíz profundamente cristiana. Y profundamente humanizadora. Persona y democracia (1958) es su obra madura acerca de la importancia de la persona en toda su reflexión filosófica. Destaca, sobre todo, la comunicación y la necesidad «de resucitar» una y otra vez ${ }^{26}$. Esta necesidad de comunicación en la condición humana es esencial, pues lo contrario, el individualismo, asfixia a la persona y ensoberbece a la sociedad.

Nos referiremos ahora a la concepción de la persona en sus últimas publicaciones: De la Aurora (1986), Notas de un método (1989) y Los bienaventurados (1990). En la primera vuelve sobre el estudio del alma humana que es el origen y en ese origen está la palabra como revelación, la palabra que crea ámbitos humanos. La aurora es luz difusa que precede a la salida del sol, por tanto busca la luz solar, metáfora del alma, de la que tenemos noticia pues radica en lo más hondo y propio del ser humano, pero no la conocemos con total claridad. La aurora se convierte en guía, horizonte de un conocimiento más amplio que el propiamente filosófico. También la describe como acontecimiento, que es más que un hecho. Pues la aurora es la raíz de lo humano, es decir, sentir originario, ahí donde la razón se hace poética. Es el interior o el carácter ontológico del ser humano, la necesidad de «conocerse para trascenderse», pues este conocimiento interior es la base de la realización humana ajena a toda alienación personal. La sabiduría está impregnada de contemplación de sí mismo, pues la aurora da paso al alba, que llega y anticipa la realidad mediante la revelación a quien, en silencio, espera este acontecimiento.

25 Zambrano, M., «Sobre una educación para la libertad», Revista de Pedagogía 156, (1934), p. 160.

26 Zambrano, M., «Fragmentos de una Ética», M-347, 1954-1955. 
Zambrano habla de acontecimiento porque reconoce que el ser humano es más que materia y por ello sólo es posible alcanzar esa sabiduría si se penetra en la interioridad del ser humano. Es el saber de las entrañas que se abre al sentir originario y así se va revelando la condición humana. Esta revelación se propone mediante un lenguaje que expresa la unidad de la filosofía y la poesía. Desentrañar el alma supone alejarse de una filosofía fisicalista que se refiere a hechos o a cosas, tangibles y medibles. La aurora se abre a una luz más clara, se sitúa en un desvelamiento que nos llega cercano, porque el alma es el propio ser de la persona, pero que no siempre se conoce, porque se requiere que la persona se entregue en el pensar y sentir, en el oir y escuchar. De ahí, que el lenguaje propuesto de 'la aurora' sea metáfora de una realidad que se siente, pero no se comprende del todo.

Una de las obras más sistemáticas de Zambrano es Notas de un método (1989), pues al tratar del método pone las bases de su filosofía. Uno de los supuestos es el valor que concede a la experiencia. A menudo llama transparencia a la percepción de esta experiencia creadora que desentraña lo concreto y lo trascendente y apela a la conciencia humana de forma inmediata. Conocer este fondo es alcanzar la autenticidad, como Ortega defendía; es la situación humana de "naufragio», que conlleva la búsqueda desesperada de pensar y orientarse a fin de salir a flote. Zambrano reconoce esta condición, pero la orientación de la filosofía y sus metáforas difieren. Denomina al hombre como un "ser sumergido» pues aun conociendo las circunstancias adversas, ansía la revelación. El ser humano tiene necesidad de tomar conciencia de sí y pasar de la «opacidad» a la «trascendencia». Este «ser sumergido» necesita la relación con otro a fin de que se le revele su propio ser. El pensarse es condición exigitiva del método, que penetra la realidad personal y desentraña la autenticidad. Propone la verdad, la esperanza y el amor como potencias que posibilitan el alcance de la trascendencia. Esta filosofía sapiencial de Zambrano convoca al ser humano a una vida auténtica que se sitúa en la persona, a fin de desvelar su ser íntegro y la realización más plena.

Por ello, Zambrano pide al método que explique pensamiento y vida. Rechaza algunos momentos históricos en los que el «método» se anquilosó en una "forma mentis», que admite solamente lo evidente sensible y deja de lado el vivir humano. La experiencia humana requiere pensarse, pero no mediante lo sensible, ni mediante los conceptos estáticos, que no penetran la vida, y dejan que el pensamiento vaya por un camino y la vida por otro. La vida es dinámica y el ser humano está en marcha y es búsqueda para lograr realizarse, porque constitutivamente es más que lo tangible, es más de lo que hace. La esperanza le abre a horizontes siempre nuevos. Esta es su condición mística. Por eso María Zambrano lo llama un ser imprevisible. Muestra esta trascendencia a través de la esperanza, como estructura del alma humana. La esperanza que le alza siempre del fracaso y de la pena. La esperanza que es razón ética y creadora. Y que se constituye también en fuente de toda convivencia, porque tiene como motivación la posibilidad de la utopía. 
En Los bienaventurados ahonda también en esta reflexión mediante esta obra que tiene un título cargado de sentido sagrado, pues acoge el modo más elevado de ser persona. Rechaza el nihilismo, el positivismo y el idealismo porque, en efecto, todos estos ismos han llenado la filosofía de sectarismos, fanatismos que no posibilitan la comprensión de la realidad en su totalidad e integridad. Cita al Maestro, como hemos visto, que «descendió hasta nuestra histórica vida», como Modelo para conocer el Absoluto y la verdadera realidad ${ }^{27}$. De este modo se sitúa frente al racionalismo moderno imperante en occidente que agrava la condena de la religión, y frente al sensualismo, que rompe la unidad del conocimiento. En Cristo se unen lo más concreto y encarnado con la transcendencia más radical y eterna. La pregunta latente podría ser la siguiente: ¿Quién puede conocer la realidad más cercana y comprender, al mismo tiempo, la realidad toda, es decir, lo cercano y su fundamento? El bienaventurado es el único que alcanza esa unidad. Pues el estado de beatitud supone una dicha, que no excluye el dolor ni los sufrimientos. Es dicha que asume el dolor. Unidad integradora sin exclusión alguna. Se trata de profundizar y comprender la condición humana de manera total. Ese logro de la razón poética, ya mencionado, que ha sido hallar la síntesis de la filosofía, la religión y la mística; se alcanza cumplidamente en esta obra, porque busca la trascendencia sin alejarse de la experiencia vital a la que quiere comprender.

Según Zambrano la filosofía se abre en su reflexión a la mística ${ }^{28}$. Y añade: «La actitud filosófica es lo más parecido a un abandono, a la partida del hijo pródigo de la casa del Padre ${ }^{29}$. El por qué de este abandono se debe a que la transcendencia se alcanza en la unidad de pensar y sentir y para alcanzarla es necesario el desprendimiento, lo cual siempre supone una vivencia mística.

Temas teológicos esenciales en el Pensamiento de M. Zambrano

a) La mística. A fin de exponer la mística en María Zambrano conviene recordar algunas características: el rechazo al racionalismo, que surge del anhelo de un pensamiento abierto al misterio, y de ahí su concepción dinámica de la filosofía mediante una razón, que no toma en cuenta sus límites, sino que se presenta abierta e integradora. Busca integrar el mundo teórico y el cotidiano, la razón y el sentir, la filosofía y la experiencia. Pues no existe separación entre los dos mundos: uno verdadero y otro sometido a la opinión y a lo subjetivo. Su concepción de la mística constituye un tema nuclear y por eso su antropología, su filosofía educativa y política están preñadas de esta reflexión. La razón poética es razón mística, porque es unitiva y trascendente y también histórica o encarnada, es razón mediadora o razón de amor. Puesto

27 Zambrano, M., Los Bienaventurados. Madrid: Siruela, 1990, p. 14.

28 Ibid, p. 77.

29 Ibid, p. 84. 
que la mística es relacional por ser razón de amor, se entiende que cuando la llamaron gnóstica, dijera que no podría serlo, porque a los gnósticos les falta caridad. Algunos estudiosos han dicho de María Zambrano que «siempre vivió de forma más religiosa que política ${ }^{30}$, ciertamente así fue su vida y de este modo respondió a las grandes cuestiones teóricas y vivenciales. Su propuesta, ante los grandes conflictos bélicos que vivió, consistió en la conversión de una razón violenta por una razón de amor y esperanza. Este fondo cristiano inspira su obra, a veces de forma explícita como en La agonía de Europa (1945).

La razón poética surge sin darse cuenta, toma tierra y aporta una mirada entrañada y sentiente, por ello teje una razón ética y no sacrificial. Es una filosofía sapiencial, una filosofía de presencia, de luz que posibilita conocer la realidad toda, pero que también saborea la ausencia, la sombra y la duda. La sombra permite ver sin deslumbramiento, reconocer lo grande y lo pequeños, lo claro y lo oscuro. En definitiva, pensar desde dentro, «desde las entrañas», porque la mística siempre parte de la experiencia vivida: Una nueva metafísica experimental que sin pretensiones de totalidad haga posible la experiencia humana, ha de estar por nacer" ${ }^{31}$. Mediante esta experiencia desde dentro se descubre lo divino, la piedad y el amor. La mística aboga por esta plenitud, lejos de todo nihilismo.

También acepta la mística porque le entusiasma la Teología del Espíritu Santo que es una teología del amor, pues consiste en una renovación interior desde las entrañas mismas y en la vivencia más religiosa. Zambrano recurre siempre al Centro, «perla preciosa», realidad más íntima del espíritu. Al centro se llega gracias al recogimiento de la mente y a la quietud de la voluntad. Se llega por la vía unitiva. El medio es la purificación, «perder para ganar», «me ha salvado hasta ahora, el no tener, el deshacerme, el derretirme como gota de cera, el borrarme, el no amarme en mi existencia» ${ }^{32}$.

Los atributos de la vida mística son: el amor, la libertad, la integridad y la esperanza. La filósofa nunca da por perdida la confianza en Dios, frente a cualquier derrota personal, pues la mística es un don recibido del Espíritu Santo que actúa en el ser humano.

b) El Espíritu Santo. Hemos de reconocer que el Espíritu Santo ha estado muy presente en toda la filosofía de la autora. En Delirio y destino escribió Delirios de la paloma donde dedicó una reflexión al Espíritu Santo porque es amor, como la Trinidad. Así quien hiere el amor, hiere el vínculo con Dios. En la carta número 15, de fecha 5 de octubre de 1974, expone las genealogías en la relación entre el Espíritu y el Logos, la genealogía griega (Padre-Sofía e Hijo) frente a la latina (Padre-Hijo-Espíritu Santo). En la carta n ${ }^{\circ} 31$ se refiere a la acción del Espíritu Santo en la vida humana. Resalta que en esta acción

30 Bundgard, A., «El pensamiento político en las obras de juventud de María Zambrano» en Actas del II Congreso Internacional sobre la vida y obra de María Zambrano (Vélez-Málaga, 1994) 151.

31 Zambrano, M., Notas de un método, op. cit., p. 164.

32 Zambrano, M., Cartas de la Pièce, op. cit, p. 164. 
están unidos todos los seres humanos por lo que el ecumenismo es realmente importante. Señala la purificación, la conversión, la inspiración como la forma de proceder del Espíritu Santo en cada ser humano... hasta llegar a decir: «es raro que algún escrito mío no acabe con referencia al Espíritu Santo sin nombrarlo, y así seguiré; quizás al final de "Notas de un Método" hable o le nombre» ${ }^{33}$. El Espíritu Santo es el santificador, y esta inspiración que el ser humano recibe requiere del ascetismo o conversión de la inteligencia, de la voluntad de todo el ser. Este deseo de conversión o transformación está también presente en la obra de Zambrano, por tanto toda unión con Dios supone antes la purificación de sí mismo.

En la Carta número 41 dialoga con los mesalianos. Estos rechazaban los sacramentos y sólo consideraban la oración, como práctica espiritual. Admitían un quietismo o impotencia del alma ante la omnipotencia divina, de modo que vería inútil todo esfuerzo o actividad de orden personal para escapar a tales poderes superiores. Fueron rechazados en el Concilio de Éfeso. ¿Pero puede ser Zambrano mesaliana o quietista? No, porque aunque acoge y analiza estas corrientes de pensamiento no las apoya, puesto que cree en la acción del Espíritu Santo, que alienta a la santidad y despierta a la virtud. "La santificación, obra del Espíritu Santo, ha de ser ejercida en el centro del ser humano y el centro no puede ser más que algo de acción continua, distribuidora, capaz de imprimir un ritmo vital; onda, pulsación de la sangre que circula y que metafóricamente corresponda a la acción vivificante» ${ }^{34}$. Reconoce que el Espíritu penetra en el alma como una espada para distinguir lo que es de lo que no es $(\mathrm{Hb} 4,12)$. El Espíritu Santo no puede concebirse sino en el seno de la Santísima Trinidad, así describe con emoción las procesiones divinas: la del Padre que nos hace hijos y la de Cristo cuyos sentimientos de la Cruz le llevan irremisiblemente al Amor.

La carta número 15 expresa con suma belleza y a través del Arte, los frescos de la Capilla Sixtina, la presencia de la Santísima Trinidad y el Amor que es y se manifiestan entre sí Padre, Hijo y Espíritu Santo: «Los cuadros en que el Padre, asomándose de su impenetrable cielo, tiende al Hijo como una bandera, como una colgadura, un instante antes - hace sentir - sobre la tierra de los hombres. El Hijo y el hermano y Señor nuestro, colgado en la Cruz. Cruz que atraviesa todas las zonas de la creación, con su costado abierto, herida, fuente (y aquí viene lo citado antes). Dios y Hombre verdadero, pues. El Espíritu Santo sobre su cabeza ya caída, doblada, y del corazón de todas las almas que uno pueda tener, sale el suspiro y el gemido del Amor; Dios mio, Dios mio, Dios mio. Y por eso somos cristianos» ${ }^{35}$. Esta es la expresión estética que deja en ella los frescos de la Capilla Sixtina.

c) La Virgen. María Zambrano menciona en múltiples ocasiones a la Virgen. En un artículo de 1989 que titula A modo de autobiografía resalta alguna de sus

33 Ibid, p. 175.

34 Zambrano, M., Cartas de la Pièce, op. cit, p. 177.

35 Ibid, p. 81. 
cualidades como la castidad o la pureza unida a la fecundidad y el dolor, un dolor que no es amargo porque es asumido y así da muchos frutos. También la Sabiduría tal como se revela, por ejemplo en el libro de Proverbios 8, 22-31. Dice Zambrano: «para mí la Virgen está identificada con el saber filosófico, y lo ampara, y lo sigue. Yo no sé si puedo decir más» ${ }^{36}$ y subraya que la Virgen no murió pues la comunicación con el Espíritu Santo es para siempre. Esta es una concepción propia de los ritos orientales que ven a María como luz del Espíritu que vive para siempre. «Sin la Virgen, criatura humana única, perfecta - por eso no muere- no sale la presencia del Espíritu Santo en el hombre y menos aún en la mujer. Ella es indispensable teológica y religiosamente y moralmente. Ella nos libra de la idolatría especialmente en ese delicadísimo punto» ${ }^{37}$.

Menciona también las oraciones que le dirige, entre otros rezos, el del rosario y también recuerda sus festividades. Por ejemplo: «día de Nuestra Señora del Carmen, cuyo escapulario me dieron a besar al "despertar" alzándolo de mi pecho, sobre mi traje de amortajada a los cuatro años. El que yo quería me vistiera para toda la vida, en su Orden. No era, no estaba de que fuese. No forcejeé» ${ }^{38}$. María se sintió varias veces cerca de la muerte y esto pudo dejar en ella esa certeza de que no era de este mundo, esa claridad acerca de la trascendencia que no era solamente un hecho teórico sino vivido existencialmente.

d) La oración. Propone la oración de recogimiento y de quietud, como los místicos enseñan. "no sé si podré. Sin violencia, con la voz propia de alma y entendimiento unidos». Ella misma emplea la palabra: «en el recogimiento donde el amor regresa herido, herido de siempre, como a su nido ${ }^{39}$. La espiritualidad que vive tiene un elemento interiorista y, a su vez, es transcendente. Así se manifiesta en sus rezos y en los que dedica a sus amigos: «Cuando rezo por ti es en silencio - ya sabes- o el Padre Nuestro ${ }^{40}$; vemos que reza mediante oraciones vocales, como son las jaculatorias, y también atiende a la oración de recogimiento que busca la contemplación más pura y más interior. Tiene en cuenta el santoral diario. Y dice que le pide cada día al Espíritu Santo que descienda en silencio.

\section{ConcLusión}

María Zambrano se nos aparece como una filósofa con el pensamiento y el sentir, lo cual es importante para la teología. No es teóloga, en el sentido de que no estructura un organum teológico, pero propone un pensamiento que

\footnotetext{
36 Zambrano, M., "A modo de autobiografía», Compluteca, 1989, 5, p. 12.

Zambrano, M., Cartas de la Pièce, op. cit, p. 83.

Ibid, p. 245.

Ibid, p. 177.

Ibid, p. 259.
} 
posibilita el acceso a Dios. Su obra suscita el pensar dentro de la teología: lo originario, las entrañas, el agua, el perdón... La teología fija un lenguaje pero éste evoluciona y la labor teológica consiste en renovar y asimilar nuevos lenguajes. En este sentido, la obra de María Zambrano suscita un lenguaje enriquecedor para la teología. La curiosidad de Zambrano le llevó a interesarse por corrientes gnósticas y plotinianas, sin embargo ella misma argumenta el rechazo por las mismas de modo que no puede considerársele ni gnóstica ni plotiniana. Incluso Agustín Andreu en el Anexo n 1 dice: «María sentía un gran respeto por la Teología Dogmática Tradicional, y muy poco por las piruetas de la Teología contemporánea...» ${ }^{41}$. En la carta 74 trata de un tema que sigue siendo actual, se acerca a la reflexión sobre el sacerdocio de la mujer y argumenta que a su juicio el varón y la mujer tienen un lugar propio cada uno, por lo que desde la tradición y el magisterio no se puede considerar que la mujer haya de acceder al sacerdocio.

Como es observable, su reflexión siempre va impregnada de experiencia abierta a la trascendencia. Podríamos decir así que la razón poética es al mismo tiempo «razón mística» o «razón espiritual» que comporta la defensa del espíritu y de un pensamiento intuitivo. Hemos considerado su pensamiento teológico aunque la autora sigue un razonamiento filosófico. Ahora bien, hemos visto que su pensamiento contiene preguntas teológicas y su reflexión tiene en cuenta la relación del hombre con Dios.

María llama Padre a Dios. Y su dedicación sobre el Padre le guía al Espíritu Santo y al sufrimiento de Cristo, que vive entre nosotros. Hemos considerado también la importancia de la reflexión sobre la Virgen pues destacarla como modelo de creyente, sólo puede hacerse desde la fe y el dogma católico. También hemos querido subrayar el sentido de la oración, comparable en algunos casos con la oración de los místicos. En realidad, la mística es una seña de identidad en la filosofía de Zambrano. Finalmente, es destacable la exaltación de la persona y su dignidad como eje axial de su filosofía, de su teología y de la vivencia mística.

Universidad Autónoma de Madrid Juana Sánchez-Gey Venegas

Dpto. de Antropología Social y Pensamiento Filosófico Español juana.sanchez-gey@uam.es

[Artículo aprobado para publicación en diciembre de 2016]

$41 \quad$ Ibid, Anexos, 299. 